\title{
Fishiness of Piscine Birds Linked to Absence of Poisonous Fungi but not Pizza
}

\author{
Martin Stervander ${ }^{1^{*}}$ and Danny Haelewaters ${ }^{2^{*} \neq}$ \\ ${ }^{1}$ Institute of Ecology and Evolution, University of Oregon, USA \\ ${ }^{2}$ Department of Botany and Plant Pathology, Purdue University, USA \\ ${ }^{\dagger}$ Present address: Department of Life Sciences, The Natural History Museum, UK \\ "Present address: Department of Biology, Ghent University, Ghent, Belgium
}

Submission: November 03, 2020; Published: December 22, 2020

Corresponding author: Martin Stervander, Institute of Ecology and Evolution, University of Oregon, Eugene, OR 97403, USA; Danny Haelewaters, Research Group Mycology, Department of Botany, Ghent University, K. L. Ledeganckstraat 35, 9000 Ghent, Belgium

\begin{abstract}
What is a species? That is one of the main questions in evolutionary biology, ecology, and conservation biology. Another question is this one: Can the degree of fish-likeness in birds be linked to the absence of poisonous fungi? Sparked by recent major ornithological advances we set out to assess whether the reason that some birds are more morphologically like fish than others could be explained by the prevalence of fungi of mild to severe toxicity. Whereas birds of several taxonomic orders are partly or predominantly aquatic, few have adapted so strongly to an underwater lifestyle as penguins (Sphenisciformes). These both eat fish and look like fish (what is up with that?), and predominantly occur in the Antarctic region, where environmental conditions largely prohibit the growth of poisonous fungi. On the other hand, birds with traditionally bird-like morphology (e.g., Gallus gallus) as well as fish with fish-like morphology (e.g., Engraulis sp.) seem to mostly occur sympatrically with mushrooms on pizzas. We thus conclude that the absence of poisonous mushrooms has led to the pronounced fishiness of certain members of class Aves. Using a sophisticated statistical framework, we also uncover an unexpected inter-class taxonomic relationship, and predict that the evolution of volant penguins because of climate change is mediated through shifted fungal distributions. Our study brings new and important perspectives to different fields, including climate change and invasion biology.
\end{abstract}

Keywords: Climate change; Convergent evolution; European Union; Mushrooms; Other stuff; R; Sphenisciformes; Taxonomic sensations

\section{Introduction}

In his pivotal contribution to the field of ornithology, Baldassarre [1] evaluated the weirdness of birds and illustrated that looking like a fish in birds is correlated with climate change [1]. This is quite surprising, because we do not know if fish themselves are even affected by climate change [2,3]- after all, they are under water. However, we are unsure about the claim that climate change may affect the fishiness of birds; no statistical analyses were done. In addition, it has been repeatedly stated that climate change may be a hoax on its own which may or may not be true-who knows, right $[4,5]$ ? At any rate, and in contrast to the above, based on previous data on the presence of poisonous mushrooms (Fungi, Basidiomycota) in the Antarctic region (probably none, but we will get back to this topic in the Discussion), we believe the fishiness of birds is correlated to fungal distributional patterns [6,7].

At the time we developed the original idea about fishiness of birds potentially being correlated to absence of poisonous mushrooms, one of the authors (D.H.) was eating pizza with four cheeses, chicken, anchovies, and mushrooms. It was really a good one, and this prompted us to-just like the pizza-integrate all four parameters in this study: fishiness, birdiness, lack of fungal toxicity, and effects of prolonged heating. We note that integrative taxonomy approaches [8], and by extension approaches to integrate everything in research, are being increasingly employed, thus supporting the rationale for the work presented in this paper.

It is important to keep in mind that research has not always been this integrative, or cross-disciplinary. For example, Charles Darwin worked alone [9] and still published a relatively well-cited contribution to the field of theology and some other disciplines. We feel it is natural for humans to dangle up and down between extremes. This is true for scientists, just like it is for politicians (consider the formation of the European Union in the 1990s and early 2000 s versus the current wish of some countries to leave again [10]).

All in all, in this study we present the results of our work with fishy birds (fide Baldassarre [1]). We hypothesize that, (1) despite 
climate change, it is still cold in Antarctica and thus the presumed lack of poisonous fungi leads to fishy-looking birds. Further, with a clear correlation of pizza and lower latitudes [11], we hypothesize that (2) birdy-looking birds (as well as fishy-looking fish) will be more prevalent than fishy-looking birds on pizzas.

\section{Material and Methods}

\section{Sampling}

Based on current avian taxonomy [12] and higher classification following Jarvis et al. [13], we randomized our selection of birds of various shapes by letting a single observer (M.S.) throw darts on a paper print-out of the world bird list while blindfolded. This resulted in two members of Galloanseres (Anas platyrhynchos, Gallus gallus), whereas remaining species belonged to Neoaves: one member of Phoenicopteriformes (Phoenicopterus plasticus) and three members of Passeriformes (Erithacus rubecula, Hirundo rustica, Passer domesticus). However, to ensure that decidedly fishy-looking species were represented, we also included two penguins (Sphenisciformes: Aptenodytes patagonicus, Spheniscus sp.) that narrowly escaped the darts. While this may be perceived as biased, we argue it is not. To further elaborate on piscine versus avian morphology, we included three representatives of Osteichtyes, namely Nemo fish (Amphiprion ocellaris), flying fish (Exocoetidae sp. indet.), and anchovy (Engraulis pizzaialis).

\section{Statistical Analyses}

The sampled taxa were ordered canonically in a two- dimensional space along the axes of avian versus piscine morphology, and the lack of poisonous fungi versus pizza. We performed a principal component analysis (PCA) using the function "prcomp" from the stats package in R v. 3.6.1 [14] after logarithmization of everything, because, hey, non-normal distributions are nasty. We also considered running generalized linear mixed models (GLMM) because they are considered fancier but decided against that on the grounds of laziness. We did not include genomic sequence data in our analyses, and therefore did not have to consider a Bayesian framework, coalescence theory, or site frequency spectra [15-17]. These are all concepts that seem so simple at the surface but can give all sorts of complex results that are difficult to interpret; thus, morphology is better than molecules [18]. Hence, we only cared about $\mathrm{p}<0.005$ and fitted an approximately quadratic trendline to our data using the Arc tool in Power point v. 16.16.21.

\section{Results}

Our PCA revealed that most of the variation in the dataset was partitioned along the first (59.3\%) and second (34.8\%) principal components (PCs), with loadings corresponding to poisonous funginess and pizza toppingness, respectively (Table 1). There is a clear bimodality in both PC scores, distinguishing on the one hand penguins (PC1, low funginess) and on the other hand anchovy and chicken (PC2, high toppingness). Plotting the scores for all taxa, a quadratic model explains the two-dimensional distribution of avian species $(p<<<0.05)$ with low residual variation except for the outlier H. rustica (Figure 1).

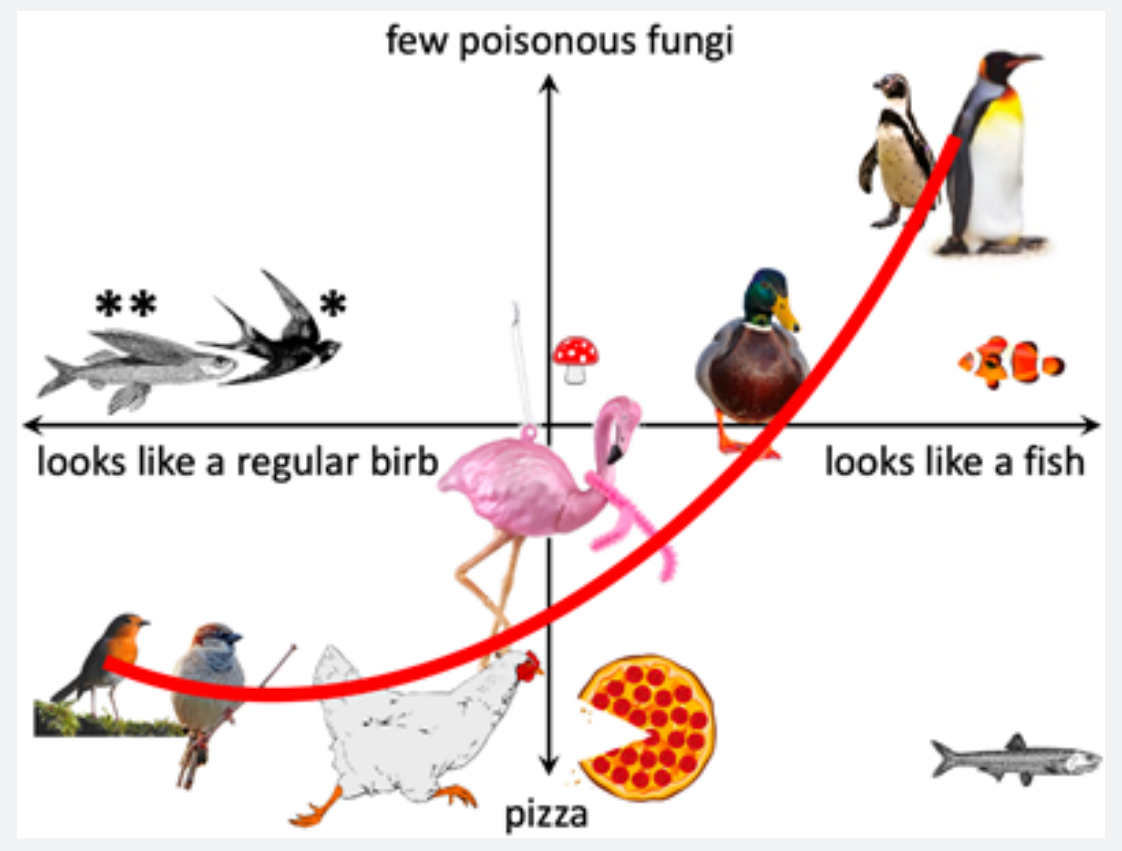

Figure 1: The relationship between (a) morphology and taxonomy in fish and birds, (b) the effect of poisonous fungal prevalence, and (c) pizza. The red line represents an approximately quadratic model across birds of an increasing fishiness. For clarity, organisms are not to scale. For a description of the taxa, see Material and Methods. For PC scores, see Table 1. Positions are indicated with asterisks for the unexpectedly closely grouping *barn swallow (Hirundo rustica) and **flying fish (Exocoetidae sp. indet.). 


\section{Oceanography \& Fisheries Open access Journal}

Table 1: Characteristics of the studied taxa, and their principal component (PC) scores for PC1 and PC2.

\begin{tabular}{|c|c|c|c|c|}
\hline Taxon & Distribution & Morphology & PC1 (poisonous funginess) & PC2 (pizza toppingness) \\
\hline Aves & & & & -13.42 \\
\hline Penguin & Antarctic & Piscine & 3.26 & -6.82 \\
\hline Duck & City ponds & Avian & 5.23 & 2.38 \\
\hline Chicken & Farms & Avian & 1.34 & -3.02 \\
\hline Robin & Forest & Avian & 7.81 & -0.56 \\
\hline House Sparrow & Everywhere & Avian & -0.39 & -4.58 \\
\hline Swallow & Predominantly sky & Avian & & -7.29 \\
\hline Osteichtyes & & & 5.09 & -1.65 \\
\hline Nemo fish & Great Barrier Reef & Piscine & 4.23 & 23.69 \\
\hline Flying fish & Ocean and air & Avian & 2.48 & \\
\hline Anchovy & Pizzas & Piscine & & \\
\hline
\end{tabular}

\section{Discussion}

We have come a far way from observational research in ornithology [19-22]. We are strong believers of research based on a well-supported rationale, good hypothesis formulation, and welldeveloped statistical analyses. In this paper, we have accounted for all three pillars of this belief. (1) The rationale is supported by an overwhelming number of studies across many fields calling for integrative work [23-32], which is exactly what we aimed to do. (2) Our hypothesis was based on data from 67 authors [6,7,33-35] (3) Our statistical approach is sound. In other words, there is no reason to assume that the work presented here may be inaccurate. We can demonstrate a clear relationship between the presumed lack of poisonous fungi and fishy-looking birds $(p<0.05$; Figure $1)$, which makes total sense, given the low ambient temperature across most of the distribution of Sphenisciformes.

On the other hand, there seems to be no such relationship for birdy-looking fish ( $p>10$; Figure 1), such as the flying fishes (family Exocoetidae), which occur predominantly in tropical and subtropical waters, at latitudes where poisonous fungi are presumed to thrive-albeit in terrestrial habitats. The close grouping of flying fish and barn swallow (Figure 1) indicates that similarities in morphological and life-history traits may have erroneously been interpreted as homoplasies [18,36]. However, our more sophisticated statistical framework suggests that instead these traits may be synapomorphies that reflect an unexpectedly close evolutionary relationship, leaving Exocoetidae as a relictual avian lineage [37]. This calls for further taxonomic evaluation, but based on our preliminary findings, we tentatively propose that family Exocoetidae is moved to a basal position within superfamily Sylvioidea [38] incertae sedis, pending further evaluation.

As for predisposition towards inclusion as pizza topping, we found a strong taxonomic disparity, with certain bird and fish species of high PC2 score (Table 1). In fact, G. gallus even runs towards the pizza (Figure 1), indicating an innate proclivity for toppingness. We acknowledge that the piscine sampling must be considered restricted compared to the avian, especially since the number of fish species [39] is triple that of bird species [12]. For example, there is recent evidence of the use of tuna (Thunnus spp.) flour in pizza base [40]. However, we have found no empirical evidence, published in either reputable or predatory journals, that the occurrence of tuna as topping would not just be cat food marketed as something more palatable.

With the advances of bird migration phenology due to climate change [41,42], we may also expect shifts in the distribution of poisonous mushrooms, even though phenological changes can be geographically asymmetric and responses in distribution changes vary between taxa $[43,44]$. To date, only one poisonous mushroom has been found in Antarctica. That is, like, literally one record: Galerina antarctica [45]. Fruiting bodies of these macro fungi (stems with caps), the "mushrooms", are otherwise never reported in Antarctica [34]. The hyphae of this mushroom are living underground, but environmental conditions-temperature and moisture-are not allowing mushroom-formation. Who would have thought? Climate change may change these conditions to become favorable (or not, see [4]).

In addition, a climate-driven expansion of the ice-free area in Antarctica from less than $1 \%$ currently to potentially $25 \%$ by the end of the century has been projected [46]. In this scenario, where the polar ice caps melt, the resulting invasion of poisonous fungi to the Antarctic region may thus exert a strong selection pressure on penguins to evolve a less fishy morphology. This would result in a marked decrease in weirdness (fide Baldassarre [1]), although we want to point out that birds can be weird in more ways than one [47] - fungi, too, now that we think about it $[48,49]$. Given that flight ability in birds can be lost remarkably rapidly [50], we postulate that climate change scenarios may soon lead to the (re-)evolution of volant penguins, and by extension the plausible expansion of Sphenisciformes ranges to pizza topping habitats. 


\section{Acknowledgement}

Nomi Wintersparv and Luna A. Haelewaters provided important feedback to the layout of Figure 1, based on crayon instructions. Dan Baldassarre, fishy penguins, and funky mushrooms all provided invaluable inspiration. Notes from Charles Darwin's daily journal during the second voyage of H.M.S. Beagle were interpreted as constructive comments on our framework. M.S. and D.H. receive mental support from the Society for Fishy Research Questions. The authors recognize that topping received much focus in this study, but also acknowledge the importance of bottoming. Finally, we would like to acknowledge that this study would not have been possible had it not been for the predatory journal industry. Without it, academia and society would be a better place.

\section{References}

1. Baldassarre DT (2020) What's the Deal with Birds? Scientific Journal of Research and Reviews 2: 2020.

2. Brander KM (2007) Global fish production and climate change. Proceedings of National Academy Sciences of the USA 104(50): 1970919714.

3. Rijnsdorp AD, Peck MA, Engelhard GH, Möllmann C, Pinnegar JK (2009) Resolving the effect of climate change on fish populations. ICES Journal of Marine Science 66(7): 1570-1583.

4. Trump DJ (2012) The concept of global warming was created by and for the Chinese in order to make U.S. manufacturing non-competitive.https: / / twitter.com/realdonaldtrump / status/265895292191248385?lang=en, accessed April 1, 2020.

5. Pachauri RK, Allen MR, Barros VR, Broome J, Cramer W, et al. (2014) Climate change 2014: synthesis report. Contribution of Working Groups I, II and III to the fifth assessment report of the Intergovernmental Panel on Climate Change. IPCC.

6. Tedersoo L, Bahram M, Polme S, Koljalg U, Yorou NS, et al. (2014) Global diversity and geography of soil fungi. Science 346(6213): 1078

7. Adams C (2014) The most dangerous mushroom. Slate. https://slate. com/technology/2014/02/most-dangerous-mushroom-death-capis-spreading-but-poisoning-can-be-treated.html, accessed April 22, 2020.

8. Haelewaters D, De Kesel A, Pfister DH (2018) Integrative taxonomy reveals hidden species within a common fungal parasite of ladybirds. Scientific Reports 8: 15966.

9. Darwin C (1859) On the Origin of Species by Means of Natural Selection. John Murray, London.

10. Clarke HD, Goodwin MJ, Goodwin M, Whiteley P (2017) Brexit Cambridge University Press.

11. Timmerman G (2019) How I found the best pizza restaurant in 13,000 cities using cloud tasks, cloud functions, and Google Maps. Medium. https://tinyurl.com/y8lm52qg, accessed January 1, 2020.

12. Gill FB, Donsker D (Eds) (2020) IOC World Bird List (v 10.1).

13. Jarvis ED, Mirarab S, Aberer AJ, Li B, Houde P, et al. (2014) Wholegenome analyses resolve early branches in the tree of life of modern birds. Science 346(6215): 1320-1331.

14. R Core Team (2019) R: A Language and Environment for Statistical Computing.
15. Drummond AJ, Suchard MA, Xie D, Rambaut A (2012) Bayesian Phylogenetics with BEAUti and the BEAST 1.7. Molecular Biology and Evolution 29: 1969-1973.

16. Heled J, Drummond AJ (2010) Bayesian inference of species trees from multilocus data. Molecular Biology and Evolution 27(3): 570-580.

17. Gutenkunst RN, Hernandez RD, Williamson SH, Bustamante CD (2009) Inferring the Joint Demographic History of Multiple Populations from Multidimensional SNP Frequency Data. PLoS Genetics 5: e1000695.

18. Mooi RD, Gill AC (2010) Phylogenies without Synapomorphies-A Crisis in Fish Systematics: Time to Show Some Character. Zootaxa 2450: 2640.

19. Wallace AR (1858) On the tendency of varieties to depart indefinitely from the original type. Proceedings of the Linnean Society of London 3: 53-62.

20. Gray GR (1862) Descriptions of a few West-African birds. Annual Magazine Natural History 10: 443-445.

21. Bocage JVB (1888) Oiseaux nouveaux de lile St Thome. Jornal de Sciencias Mathematicas, Physicas e Naturaes de Lisboa 12: 229-232.

22. Schufeldt RW (1913) Further studies of fossil birds with descriptions of new and extinct species. Bulletin of the American Museum of Natural History 32: 285-306.

23. Abiven S, Altermatt F, Backhaus N, Deplazes-Zemp A, Furrer R, et al (2017) Integrative research efforts at the boundary of biodiversity and global change research. Current Opinion Environmental Sustainability 29: 215-222.

24. Liu F, Li Z (2019) Integrative Omics Approach for the Community Function Evaluation of Sponge and Coral Microbiomes. In: Symbiotic Microbiomes of Coral Reefs Sponges and Corals. Springer, pp. 171-179.

25. Abrahams B, Sites N, Ester KJ (2019) Exploring integrative research in the context of invasive alien plant management. South African Journal of Science 115(3): 64-74.

26. Bell KC, Carlson CJ, Phillips AJ (2018) Parasite Collections: Overlooked Resources for Integrative Research and Conservation. Trends in Parasitology 34(8): 637-639.

27. Di Baldassarre G, Nohrstedt D, Mard J, Burchardt S, Albin C, et al. (2018) An Integrative Research Framework to Unravel the Interplay of Natural Hazards and Vulnerabilities. Earth's Future 6(3): 305-310.

28. Dubey RK, Tripathi V, Dubey PK, Singh HB, Abhilash PC (2016) Exploring rhizospheric interactions for agricultural sustainability: the need of integrative research on multi-trophic interactions. Journal of Cleaner Production 115: 362-365.

29. Horowitz CR, Orlando LA, Slavotinek AM, Peterson J, Angelo F, et al. (2019) The Genomic Medicine Integrative Research Framework: A Conceptual Framework for Conducting Genomic Medicine Research. American Journal of Human Genetics 104: 1088-1096.

30. McWilliams N (2017) Integrative Research for Integrative Practice: A Plea for Respectful Collaboration Across Clinician and Researcher Roles. Journal of Psychotherapy Integration 27: 283-295.

31. Sevcikova T, Growkova K, Kufova Z, Filipova J, Vrublova P, et al. (2017) Biobanking strategy and sample preprocessing for integrative research in monoclonal gammopathies. Journal of Clinical Pathology 70(10): 847-853.

32. Tress G, Tress B, Fry G (2005) Clarifying integrative research concepts in landscape ecology. Landscape Ecology 20: 479-493.

33. Pringle A, Vellinga EC (2006) Last chance to know? Using literature to explore the biogeography and invasion biology of the death cap mushroom Amanita phalloides (Vaill. Ex fr. :Fr.) link. Biological Invasions 8: 1131-1144. 
34. Ruisi S, Barreca D, Selbmann L, Zucconi L, Onofri S (2006) Fungi in Antarctica. Reviews in Environmental Science and Bio/Technology 6: 127-141.

35. Tulloss RE (2005) Amanita - beauty, danger, and diversity - almost everywhere. NJMA News 35: 7-11.

36. Kukalova-Peck J (2008) Phylogeny of higher taxa in insecta: Finding synapomorphies in the extant fauna and separating them from homoplasies. Evolutionary Biology 35: 4-51.

37. Alstrom P, Hooper DM, Liu Y, Olsson U, Mohan D, et al. (2014) Discovery of a relict lineage and monotypic family of passerine birds. Biology Letters 10: 1020131067.

38. Alstrom P, Olsson U, Lei F (2013) A review of the recent advances in the systematics of the avian superfamily Sylvioidea. Chinese Birds 4(2): 99-131.

39. Near TJ, Eytan RI, Dornburg A, Kuhn KL, Moore JA, et al. (2012) Resolution of ray-finned fish phylogeny and timing of diversification. Proceedings of National Academy Sciences of the USA 109(34): 1369813703.

40. Campelo DAV, Souza MLRd, Moura LBd, Xavier TO, Yoshida GM, et al (2017) Addition of different tuna meal levels to pizza dough. Brazilian Journal of Food Technology 20: e2016014.

41. Stervander M, Lindstrom A, Jonzen N, Andersson A (2005) Timing of spring migration in birds: long-term trends, North Atlantic Oscillation and the significance of different migration routes. Journal of Avian Biology 36(3): 210-221.

42. Jonzen N, Linden A, Ergon T, Knudsen E, Vik JO, et al. (2006) Rapid advance of spring arrival dates in long-distance migratory birds.
Science 312: 1959-1961.

43. Lehikoinen A, Linden A, Karlsson M, Andersson A, Crewe TL, et al. (2019) Phenology of the avian spring migratory passage in Europe and North America: Asymmetric advancement in time and increase in duration. Ecological Indicators 101: 985-991.

44. Devictor V, van Swaay C, Brereton T, Brotons L, Chamberlain D, et al. (2012) Differences in the climatic debts of birds and butterflies at a continental scale. Nature Climate Change 2: 121-124.

45. Rejcek P (2012) Mushrooms found near Palmer Station appear to be common but very poisonous. The Antarctic Sun. https://tinyurl.com/ y8kfw9rl, accessed April 22, 2020.

46. Lee JR, Raymond B, Bracegirdle TJ, Chades I, Fuller RA, et al. (2017) Climate change drives expansion of Antarctic ice-free habitat. Nature 547: 49-54.

47. Stervander M, Ryan PG, Melo M, Hansson B (2019) The origin of the world's smallest flightless bird, the Inaccessible Island Rail Atlantisia rogersi (Aves: Rallidae). Molecular Phylogenetics and Evolution 130: 92-98.

48. Blackwell M, Haelewaters D, Pfister DH (2020) Laboulbeniomycetes: Evolution, natural history, and Thaxter's final word. Mycologia 112(6): 1048-1059.

49. Desjardin DE, Peay KG, Bruns TD (2017) Spongiforma squarepantsii, a new species of gasteroid bolete from Borneo. Mycologia 103: 11191123.

50. Campagna L, McCracken KG, Lovette IJ (2019) Gradual evolution towards flightlessness in steamer ducks. Evolution 73(9): 1916-1926.

\section{Author contributions:}

D.H. and M.S. provided equal intellectual input into conception, design, analyses, and writing. C.D. oversaw the research, but deceased prior to submission and thus could not confirm authorship.

This work is licensed under Creative Commons Attribution 4.0 Licens

DOI: $10.19080 /$ OFOAJ.2020.12.555850
Your next submission with Juniper Publishers will reach you the below assets

- Quality Editorial service

- Swift Peer Review

- Reprints availability

- E-prints Service

- Manuscript Podcast for convenient understanding

- Global attainment for your research

- Manuscript accessibility in different formats ( Pdf, E-pub, Full Text, Audio)

- Unceasing customer service

Track the below URL for one-step submission https://juniperpublishers.com/online-submission.php 